\title{
Location of the prlC (opdA) Gene on the Physical Map of Escherichia coli
}

\author{
CHRISTOPHER A. CONLIN AND CHARLES G. MILLER* \\ Department of Microbiology, University of Illinois at Urbana-Champaign, Urbana, Illinois 61801
}

Mutations at the prlC locus were first identified as extragenic suppressors of the protein localization defect caused by certain $\operatorname{lam} B$ signal sequence mutations (5). We have shown that prlC is the Escherichia coli homolog of the Salmonella typhimurium gene opdA, which encodes metallopeptidase oligopeptidase A (4). We have sequenced both of these genes and shown that their nucleotide sequences are $84 \%$ identical (4). Sequence comparisons with other proteases have shown that OpdA and PrlC are members of a class of metallopeptidases which includes enzymes from rats, pigs, Schizophyllum commune, and Saccharomyces cerevisiae. Another peptidase, dipeptidyl carboxypeptidase, the product of the $d c p$ gene found in $E$. coli and $S$. typhimurium, is also a member of this group of enzymes $(2,3)$. Recent work in our laboratory has shown that opd $A$ is a previously uncharacterized $\sigma^{32}$-dependent heat shock gene (3). Since the promoter region of prlC is identical to that of the corresponding region of $\operatorname{opd} A$, we believe that $p r l C$ is also a heat shock gene.

Phage P22 cotransduction of genetic markers clearly placed opdA at 76 map units on the Salmonella chromosome, between asd (75 map units) and $x y l B$ (78 map units) (2). However, phage P1 cotransduction in the MC4100 strain background suggested that $\mathrm{prlC}$ was located at $71 \mathrm{~min}$ on the $E$. coli chromosome $(11,12)$. To localize $p r l C$ on the physical map of $E$. coli, we made a probe from a 708-bp internal fragment of opdA the sequence of which is $88 \%$ identical to prlC. This probe was hybridized to the Kohara miniset (7). After high-stringency washes $(1 \times$ SSC [ $1 \times$ SSC is $0.15 \mathrm{M}$ $\mathrm{NaCl}$ plus $0.015 \mathrm{M}$ sodium citrate] $-0.1 \%$ sodium dodecyl sulfate) $\left.(10), 65^{\circ} \mathrm{C}\right)$, a hybridization signal was obtained from only one phage clone, 12E4(608), and not from the neighboring clones 4D9(607) and 6A4(609) (Fig. 1). These results suggested that the probe sequence was entirely contained in the 1.4-kb gap between 4D9(607) and 6A4(609). To confirm this location, restriction enzyme sites in the prlC sequence were compared with those in the $E$. coli chromosome with the MapSearch program $(8,9)$. The sites matched perfectly the region from 3663.9 to $3666 \mathrm{kbp}$ on the physical map of Rudd (8). (The published prlC sequence contains an error which predicts a $B g l I$ site not present on the physical map. Restriction digests do not show this site, however, and resequencing of this region resulted in correction of an error [CG at positions 461 and 462 should be GC] which removes the $B g l$ I site.) These results (Fig. 1) show that prlC is located at 78.4 map units; this location is between the positions on the $E$. coli chromosome of asd at 75.7 map units and $x y l B$ at 80.1 map units (1) and is thus analogous to the 76-map-unit location of opdA in $S$. typhimurium. The prlC gene is transcribed in the counterclockwise direction in both species. This position differs from the map position determined

\footnotetext{
${ }^{*}$ Corresponding author. Electronic mail address: CHARLES_
} MILLER@QMS1.life.uiuc.edu. by cotransduction of genetic markers $(11,12)$. We do not understand the basis for this difference although it may be worth noting that the strain used for the transductional mapping, MC4100, has been shown to differ from W3110 in this region (6).

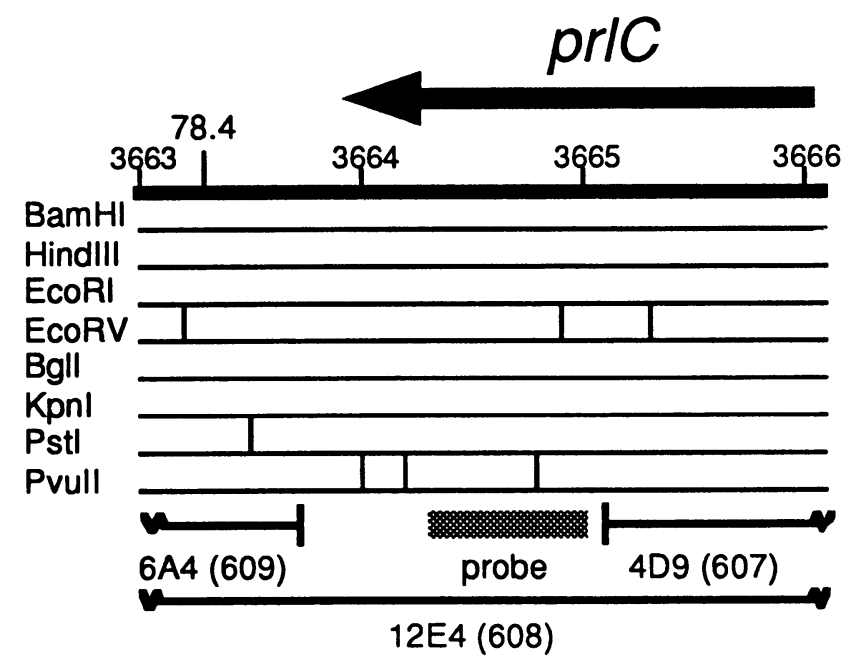

FIG. 1. Restriction map of $E$. coli chromosome from 3663 to 3666 kbp showing the location and direction of transcription of the prlC gene, position of the probe used to hybridize to the Kohara miniset of phage clones, and regions contained on clones 4D9(607), 12E4(608), and 6A4(609).

This work was supported by grant AI10333 from the National Institute for Allergy and Infectious Diseases awarded to C.G.M.

\section{REFERENCES}

1. Bachmann, B. J. 1990 . Linkage map of Escherichia coli K-12, edition 8. Microbiol. Rev. 54:130-197.

2. Conlin, C. A., and C. G. Miller. 1992. Cloning and nucleotide sequence of $o p d A$, the gene for oligopeptidase A from Salmonella typhimurium. J. Bacteriol. 174:1631-1640.

3. Conlin, C. A., and C. G. Miller. Unpublished observations.

4. Conlin, C. A., N. J. Trun, T. J. Silhavy, and C. G. Miller. 1992. Escherichia coli prlC encodes an endopeptidase and is homologous to the Salmonella typhimurium opdA gene. J. Bacteriol. 174:5881-5887.

5. Emr, S. D., S. Hanley-Way, and T. J. Silhavy. 1981. Suppressor mutations that restore export of a protein with a defective signal sequence. Cell 23:79-88.

6. Miller, J. H. (ed.). 1992. A short course in bacterial genetics. Cold Spring Harbor Laboratory, Cold Spring Harbor, N.Y.

7. Kohara, Y., K. Akiyama, and K. Isono. 1987. The physical map of the whole $E$. coli chromosome: application of a new strategy for rapid analysis and sorting of a large genomic library. Cell 50:495-508. 
8. Rudd, K. E. 1992. Alignment of $E$. coli DNA sequences to a revised, integrated genomic restriction map. In J. H. Miller (ed.), A short course in bacterial genetics. Cold Spring Harbor Laboratory, Cold Spring Harbor, N.Y.

9. Rudd, K. E., W. Miller, C. Werner, J. Ostell, C. Tolstoshev, and S. G. Satterfield. 1991. Mapping sequenced $E$. coli genes by computer: software, strategies and examples. Nucleic Acids Res. 19:637-647.

10. Sambrook, J., E. F. Fritsch, and T. Maniatis. 1989. Molecular cloning: a laboratory manual, 2nd ed. Cold Spring Harbor Laboratory Press, Cold Spring Harbor, N.Y.

11. Trun, N. J. 1988. Ph.D. thesis. Princeton University, Princeton, N.J.

12. Trun, N. J. and T. J. Silhavy. 1989. PriC, a suppressor of signal sequence mutations in Escherichia coli, can direct the insertion of the signal sequence into the membrane. J. Mol. Biol. 203: $665-676$. 